\title{
Resistivity-induced Polarization Receiver/Transmitter Design and PC-assisted Data Analysis
}

\author{
Abdülkadir Çakır ${ }^{1}$, Seyit Akpancar ${ }^{2}$ \\ ${ }^{1}$ Department of Electrical and Electronics Engineering, Faculty of Technology, \\ Suleyman Demirel University, Isparta, Turkey \\ E-mail: abdulkadircakir@sdu.edu.tr \\ ${ }^{2}$ Department of Computer Programming, Atabey Vocational School, Suleyman \\ Demirel University, Isparta, Turkey \\ E-mail: seyitakpancar@sdu.edu.tr
}

\begin{abstract}
Resistivity-induced polarization is a method that is used to identify underground layers by resistivity. In this study, a resistivity induced polarization receiver/transmitter device was designed using the CCS C programming language and tested. The most outstanding feature of the implemented system is that the connection between the receiver and the transmitter were enabled by wireless bluetooth. The data obtained by this system were sent to a PC via wireless bluetooth connection and the data were analyzed after being processed by a program in C\# language. The system has 55 volt, 110 volt, 220 volt output amplitudes, as direct or alternating current. The frequency of the current used in the system is $0.1 \mathrm{~Hz}, 0.3 \mathrm{~Hz}, 1 \mathrm{~Hz}$, and $3 \mathrm{~Hz}$, and the signals follow the square wave amplitude form. The system was designed to be user-friendly by LCD monitors, which were used to detect the amplitude and frequency of the current sent to the underground.
\end{abstract}

Keywords: Resistivity IP; geological structure; resistivity; bluetooth

\section{Introduction}

Even today, many countries in the world intensively experience geological formations. This dynamic structure of the underground causes landslides and underground clearance. It is crucial for today's technological world to forsee these geological formations in order to identify the locations that are suitable for residential areas.

Underground research is not conducted solely for predicting earthquakes. For instance, in agriculture, which plays a vital role in many economies around the world, watering is critically important. Considering that surface water agricultural opportunities are limited in many countries around the world, this surface water 
shortage necessitates utilizing underground water supplies. Accordingly, identifying the water supplies and productive location underground is extremely significant regarding economics and labour force.

\section{Underground Research Systems}

Geophysics engineering, which studies the issues of identifying and examining the locations of mines, minerals, fuel, natural gas, or water underground has specific research and measuring methods. The methods used in this engineering area are seismic, gravity, electrical-electro-magnetic, magnetic, thermal, radioactive, and remote sensing. In the research of underground mineral resources, geophysical methods research practices on the differences between the physical features of minerals and the physical features of the location where these minerals are located (density, wave velocity, electrical conductivity, and magnetic sensitivity).

The method or methods to be used in underground research is crucial for the reliability of the results. Considering the theoretical application capacity, field condition adeptness, and expenditure of the methods, the geoelectrical resistivity method appears to be the most appropriate method.

Every substance in the world has specific parameters such as resistivity, density, and specific heat. Resistivity maps of the mineral layers underground are drawn via the electrical resistivity method, which calculates the resistivity of the substances, which are located as layers underground, to an electric current. These maps illustrate water resources, fuel, or various metal reservoirs underground [1].

Today, the developments in electrical resistivity systems require employing computational methods in the phase of the evaluation of the data. In particular, the basic algorithms, in which forward and inversion modelling are used in the evaluation of geophysical data, require computational assessment. A direct formula is the basic evaluation approach of geophysics, which is described as the assessment of the reaction caused by a model, starting from an underground model with known parameters [2].

Finite differences and elements methods are becoming the most popular computational methods in forward modelling. These developments in computational assessments enable point and two-dimensional electronic data assessments to be realized to facilitate electrode permutation.

\subsection{Electrical Resistivity}

Underground geological substances have characteristic features such as resistivity, acoustical impedance, magnetic sensitivity, and density. In the chemical structure of the substance, resistivity differs according to the types and strength of the 
fastening points of atomic bonds. The bonding strength of the atomic bonds reveal electrical resistivity, which is specific to the substance, according to the reactive resistivity that the substance shows towards the current [3]. Table 1 shows the electrical resistivity of some substances in the ground.

Table 1

Electrical resistivity of some of the substances

\begin{tabular}{|l|l|}
\hline Element & Resistivity $(\Omega \mathrm{m})$ \\
\hline Chalcopyrite & $1,5 \times 10^{-5}-3 \times 10^{-1}$ \\
\hline Pyrite & $2,9 \times 10^{-5}-1,5$ \\
\hline Hematite & $3,5 \times 10^{-3}-10^{7}$ \\
\hline Limonite & $10^{3}-10^{7}$ \\
\hline Ilmenite & $10^{-3}-5 \times 10$ \\
\hline Rock Salt & $3 \times 10^{2}-10^{13}$ \\
\hline Hard Coal & $10^{-3}-2 \times 10^{5}$ \\
\hline Granite & $3 \times 10^{2}-10^{6}$ \\
\hline Sand(40\%shale $)$ & 8 \\
\hline Sea Water & $3 \times 10^{-1}$ \\
\hline Lignite & $9-2 \times 10^{2}$ \\
\hline
\end{tabular}

\begin{tabular}{|l|l|}
\hline Element & Resistivity $(\Omega \mathrm{m})$ \\
\hline Soil (Top) & $250-1700$ \\
\hline Dry Sandy Soil & $80-1050$ \\
\hline Sand and Gravel & $30-225$ \\
\hline Silt (Dry) & 1400 \\
\hline Silt (Saturated) & 100 \\
\hline Marble & $10^{2}-2,5 \times 10^{8}$ \\
\hline Sandstone & $1-7,4 \times 10^{8}$ \\
\hline Limestone & $5 \times 10-10^{7}$ \\
\hline Dolomite & $3,5 \times 10^{2}-5 \times 10^{3}$ \\
\hline Alluvium and Sand & $10-8 \times 10^{2}$ \\
\hline Pure Ground Water & $10-100$ \\
\hline
\end{tabular}

\section{Geoelectrical Methods Used in Underground Research}

Underground resistivity dispersion is identified via surface measurements. In surface measurements, in order to measure the potential difference of the current produced by two conductive electrodes, which are used to transmit electricity underground, resistivity dispersion underground is identified with two potential electrodes [4].

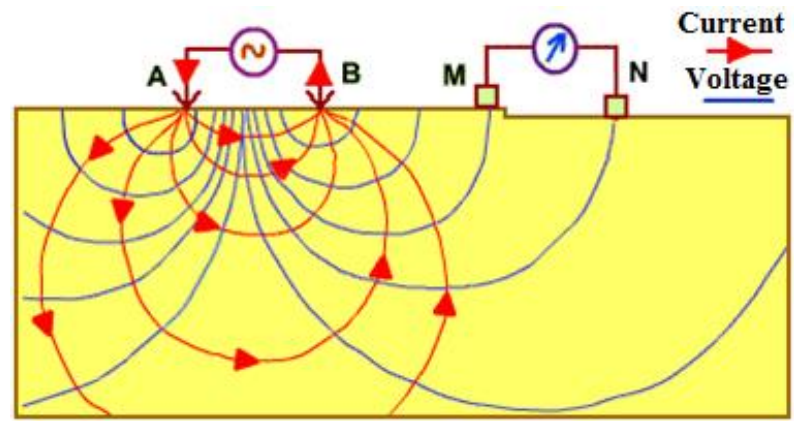

Figure 1

Electricity resistivity method 
Figure 1 shows the distribution of current lines that are produced by the electrodes shown with the rows in the A-B range and as a result of this current, the distribution of the electrical stress (electrical potential) created in $\mathrm{M}-\mathrm{N}$ range current lines [5].

Underground resistivity distribution depends on the type and form of the resource, type of the current transmitted underground, and on the distance between the resource and the receiver [6]. Therefore, it is critical to decide the most convenient one between the self-potential and induced polarization geoelectrical methods according to the geological structure.

\subsection{Self-Potential Method}

The self-potential method is based on the measurement of the potential variation of the resistance between two points in the earth. It is the only geoelectrical method that allows the opportunity to implement the method without transmitting an electrical current underground. This feature of the self-potential method makes its usage easy and its implementation simple. This method measures the natural electricity current underground [7]. Especially, this method is successfully used in the identification of sulfa-minerals, which can be oxidized such as pyrite, chalcopyrite, galena, molybdenite, and their extensions and horizontal locations.

Generally, metallic stakes are used in order to measure the potential difference between two points. However, in the measurement of self-potential, using metallic stakes is not a reliable method. This is one of the critical disadvantages of the selfpotential method. A variable electrolytic potential difference exists between the metallic electrode driven in the ground and the ground. In particular, this situation is distinctly observable when the ground is wet. Additionally, these induced potentials which occur between electrodes and the ground are erratic and vary according to the location and time. Therefore, self-potential measurements should be realized with the electrodes that are not polarized instead of metallic stakes [8].

\subsection{Induced Polarization Method}

In the resistivity method, an electricity current is transmitted underground with the help of two electrodes that are connected to a power plant or battery system. In order to measure the reaction of the ground when the voltage variation is examined from a different point with an electrode, a delay is observed in the reactions of the ground. In particular, when the welding current is shut instantly, the voltage value does not drop to zero. This impact is called induced polarization.

There are two different ways to carry current between two electrodes placed in points A-B in Figure 1, called faradaic and non-faradaic currents (Figure 2). With the transmission of a faradaic current the result is an electrochemical reaction of some ions and the spread of those ions in the underground interfacial layers. The current is physically carried through electron transfer from the interfacial layer. 


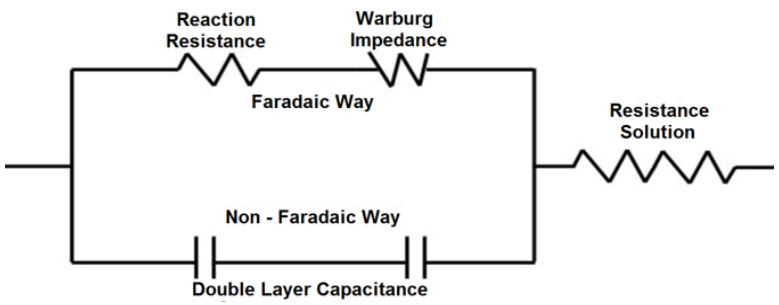

Figure 2

The path of current in the ground

A significant amount of the current above $1000 \mathrm{~Hz}$ is carried through the interfacial layer in a non-faradaic way. Therefore, it changes according to internal resistivity frequency of interface. As the frequency is lowered, more current transmits through faradaic way [9]. Consequently, frequency and wave form of the current sent underground have the utmost importance in the induced polarization method.

Induced polarization used in geophysics is measured through voltage variation in time or frequency impact. These two induced polarization methods are essentially similar to each other.

Time setting measurements: When the current sent underground is terminated in an instant, the voltage rate creates a damping or discharge curve (Figure 3).

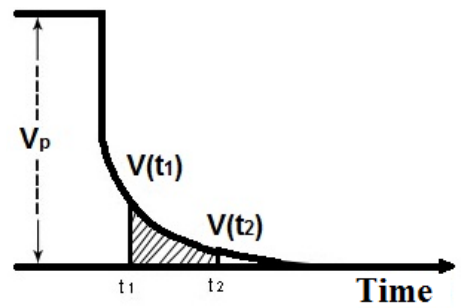

Figure 3

Voltage damping graphic in time setting measurements

Transferring and breaking current times are called "current on" and "current off". This transaction is repeated several times in order to clear the voltage rate on the substance underground, which is created by the current sent to the underground, from the noise [10]. The $\Delta \mathrm{V}$ voltage, shown in the fields of Figure 3 is calculated, generally, when the square wave current is sent underground for 3 seconds on, and 3 seconds off, and the integral time is 0.5 and 1.5 seconds.

Accuracy in several implementations of the current transmissions to the underground in very short time spans has a critical impact on the results. Consequently, it is important for the measuring instruments be highly sensitive towards the data produced within the time spans of "current on" and "current off". 
This method is fully accomplished by the identification of sulphuric mineral strata, and underground water, and ground studies.

Frequency environment measurement: Induced polarization impacts are observed in frequency environments as well. By and large, measurements realized in the frequency environment are below $10 \mathrm{~Hz}$. The current is transmitted underground at two different frequencies. The frequency of the first current should be rather low (close to direct current). The visible resistance values in these two frequencies are called frequency effect (FE). Frequency effect is calculated with equation 1.

$F E=\frac{\left[\rho_{D C}-\rho_{A C}\right]}{\rho_{A C}}$

$F E$ : Frequency effect

$\rho_{A C}$ : Visible resistivity value at high frequency

$\rho_{D C}$ : Visible resistivity value at low frequency

In practice, the value of one frequency is ten times higher than the value of other frequency, such as $\mathrm{f} 1=0.1 \mathrm{~Hz}, \mathrm{f} 2=1$.

Frequency effect is also called frequency effect percentage (FEP) as in equation 2.

$F E P=100 \times F E$

FEP: Frequency effect percentage

FE: Frequency effect

Another parameter used in the frequency setting method is metallic factor. The metallic factor is proposed in order to minimize the effects of the parameters, such as, electrolyte, heat, and pore size. The metallic factor is calculated through equation3 [10].

$M F=\frac{F E P}{\rho_{D C}} \times 2 \pi \times 10^{3}$

$M F:$ Metallic factor

FEP: Frequency effect percentage

$\rho_{D C}$ : Visible resistivity value at lower frequencies

In frequency setting measurements, by examining the changes of the values of visible resistivity and the metallic factor, the location of the mineral stratum is ascertained. This process usually depends on the principle that as the frequency of the current sent underground increases, the resistance of the rocks underground decreases. The induced polarization effect is mostly seen between the frequencies of 0.1 and $20 \mathrm{~Hz}$ [9]. Higher frequencies are not preferred because of their high electromagnetic induction effect. 


\section{Description of System}

The system proposed in this study consists of three basic parts (Figure 4). These include:

- Transmitter unit

- Receiver unit

- Evaluation Program

The transmitter and receiver units can operate in correlation with each other or independently from each other. The software developed for the evaluation of the data is designed in a way that it can operate independently from these two units, likewise.

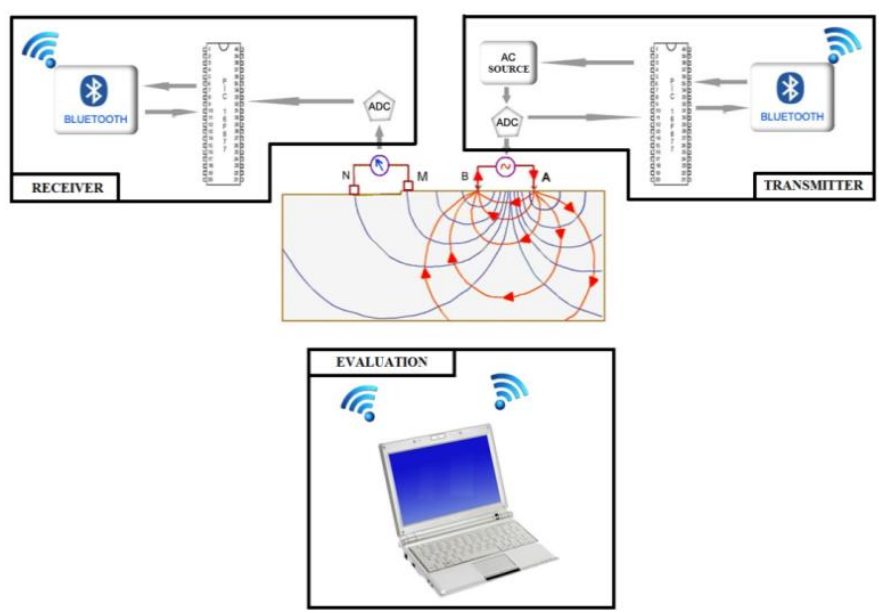

Figure 4

The block diagram of the resistivity IP system proposed in this study

\subsection{Transmitter Unit}

The transmitter unit designed and developed for this study produces the current to be transmitted underground and measures the current absorbed underground as well.

As is pictured in Figure 5 in a block diagram, the transmitter unit consists of four parts: power stage, frequency stage, control stage, and PC connection stage. 


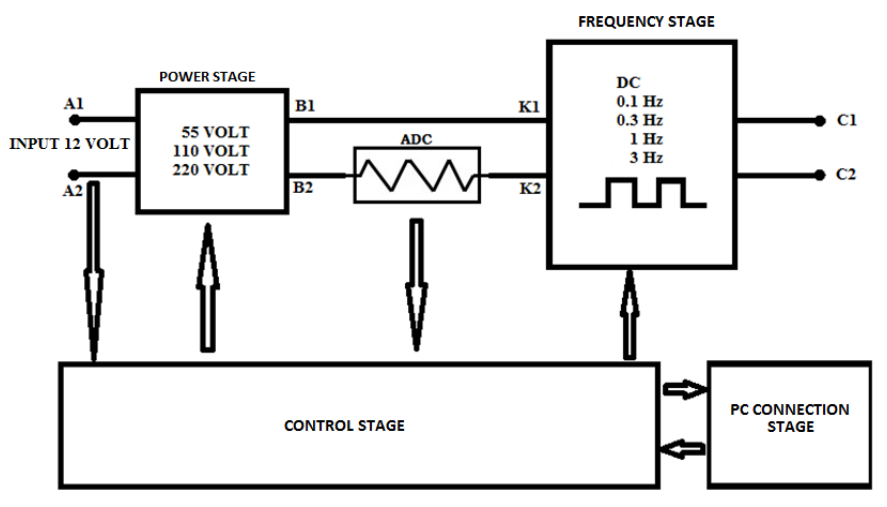

Figure 5

Block diagram of the transmitter unit

A 12 volt amplitude direct current is applied through A1 and A2 points via the transmitter unit. After the amplitude is increased to 55 volts, 110 volts, or 220 volt at the power stage, it is sent to points B1 and B2. The current transmitted through point B2 is measured with a PIC analog digital converter at the control stage, then enters to the frequency stage from points $\mathrm{K} 1$ and $\mathrm{K} 2$. After converted to $0.1 \mathrm{~Hz}$, $0.3 \mathrm{~Hz}, 1 \mathrm{~Hz}$, or $3 \mathrm{~Hz}$ square wave or as unconverted, the direct current that enters the frequency stage from points $\mathrm{K} 1$ and $\mathrm{K} 2$ is sent to points $\mathrm{C} 1$ and $\mathrm{C} 2$, which are the last steps of the process of the transmission of the current underground.

\subsubsection{Power Stage}

This study designed and developed the circuit as it is pictured in Figure 6, which increases the 12 volt current applied from points A1 and A2 of the transmitted unit to 55 volts, 110 volts, or 220 volts and converts the current into accurate direct current through filtering [11].

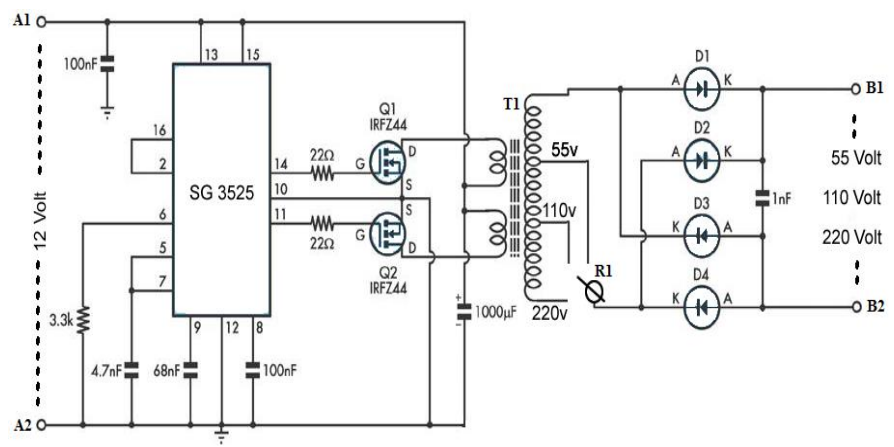

Figure 6

Power stage circuit diagram of the transmitter unit 
In the circuit, a $100 \mathrm{~Hz}$ square wave signal, which is produced through a SG3525 integrated unit, is applied to the primary windings of the T1 transformator through Q1 and Q2 power MOSFETs (metal oxide semiconductor field effect transistors).

The MOSFETs used in the circuit are resistant up to a 50 ampere current [12].In order to prevent the MOSFETs from being destroyed in the case that they overheat when a high current is drawn, MOSFETs are looped to heatsinks.

A 12 volt voltage applied from the primary winding of the T1 transformator is converted to 55 volt, 110 volt, and 220 volt at the secondary winding. The R1 relay is responsible for selecting the transformed voltages. A $100 \mathrm{~Hz}$ voltage alternating current chosen by the $\mathrm{R} 1$ relay is transformed into a direct current through diodes D1, D2, D3, and D4 and sent to points B1 and B2.

\subsubsection{Frequency Stage}

DC current in the power stage is used to convert $0.1 \mathrm{~Hz}, 0.3 \mathrm{~Hz}, 1 \mathrm{~Hz}$ or $3 \mathrm{~Hz}$ square wave by the circuit in Figure 7.
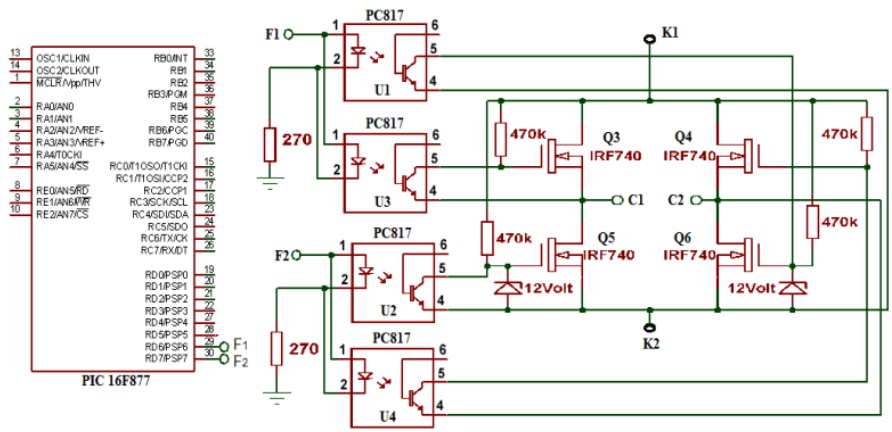

Figure 7

Frequency stage circuit diagram of the transmitter unit

The $0.1 \mathrm{~Hz}, 0.3 \mathrm{~Hz}, 1 \mathrm{~Hz}$, or $3 \mathrm{~Hz}$ frequency signal is generated by using the CCS $\mathrm{C}$ programming language in the PIC16F877 microcontroller and inverter circuit, as shown in Figure 7.

When point F1 of the inverter circuit is logic-1, the Q3 and Q6 MOSFETs are switched; when point F2 is logic-1, the Q4 and Q5 MOSFETs are switched. The direct current derived from the power stage, which is looped to points $\mathrm{K} 1$ and $\mathrm{K} 2$, is transformed into the square wave form at the $\mathrm{C} 1$ and $\mathrm{C} 2$ collector points through the double cross switching of the MOSFETs. The waveforms in Figure 8 are the square wave forms, which are observed through the oscilloscope at the $\mathrm{C} 1$ and $\mathrm{C} 2$ collector points. 
DC
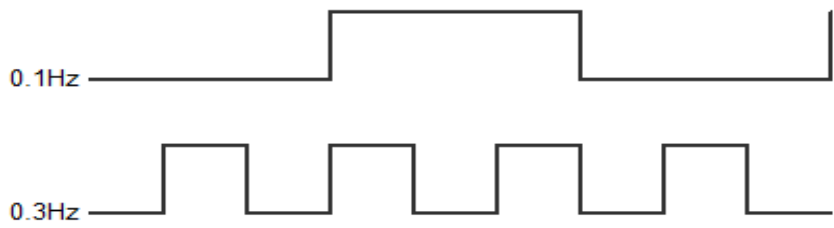

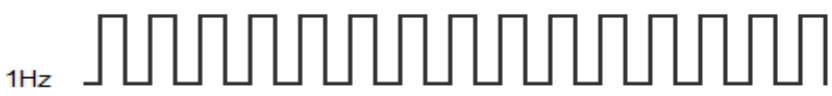
$3 \mathrm{~Hz}$

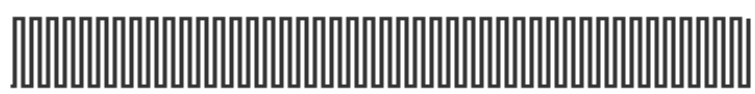

Figure 8

Wave forms of $\mathrm{C} 1$ - $\mathrm{C} 2$ collectors in the transmitter unit

\subsubsection{PC Connection Stage (Bluetooth)}

It is extremely important to obtain the value of the current sent to the underground through $\mathrm{C} 1$ and $\mathrm{C} 2$ collector points of the transmitter unit carried out in this study, as well as to transfer the related data to the computer where the data to be evaluated. After the current data, which is received as analogue, is processed in PIC and transformed into digital data, it is sent to the computer via the bluetooth module circuit in Figure 9.

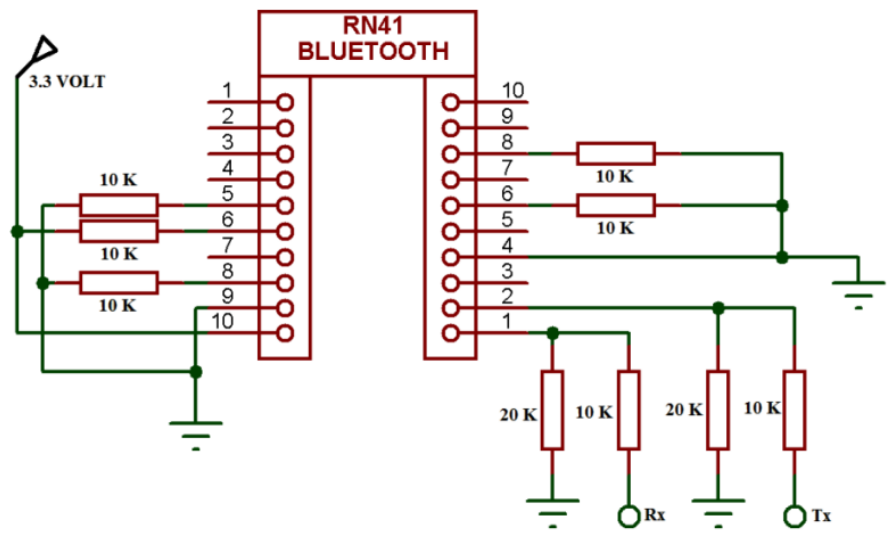

Figure 9

Connection stage circuit diagram of the transmitter unit

The circuit in Figure 9 was designed and activated for the RN41 bluetooth module, which connects the transmitter unit, $\mathrm{PC}$, and the receiver unit. 
The connection between the transmitter unit, receiver unit, and the PC is achieved through connecting the $\mathrm{Rx}$ and $\mathrm{Tx}$ points in the circuit with $\mathrm{C} 6$ and $\mathrm{C} 7$ pins, respectively, of PIC in the control stage. The top view of the bluetooth module is seen in Figure 10.

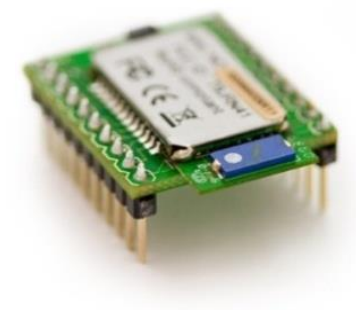

Figure 10

RN41 bluetooth module for PC connection

\subsubsection{Control Stage}

The designed control stage executes all the administrative functions of the transmitter unit. The PIC in Figure 11 which constitutes the base of the control stage, measures charge of the transmitter unit source in percentage shown on the LCD monitor. Voltage and frequency choices can be seen on the LCD monitor menu, and the values are arranged through operating relays connected to the D6 and D7 pins of the PIC according to the choices of the user. Additionally, via communication with the bluetooth kit, the transaction of sending the current and frequency data is received from the receiver unit by the PC.

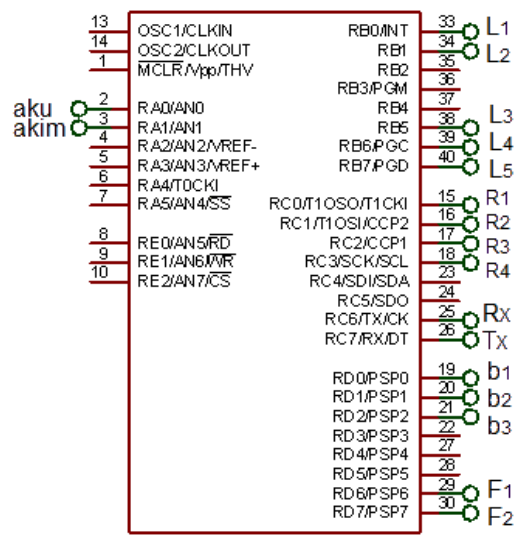

Figure 11

Control PIC of the transmitter unit 
The top view of the transmitter unit is seen in Figure 12.

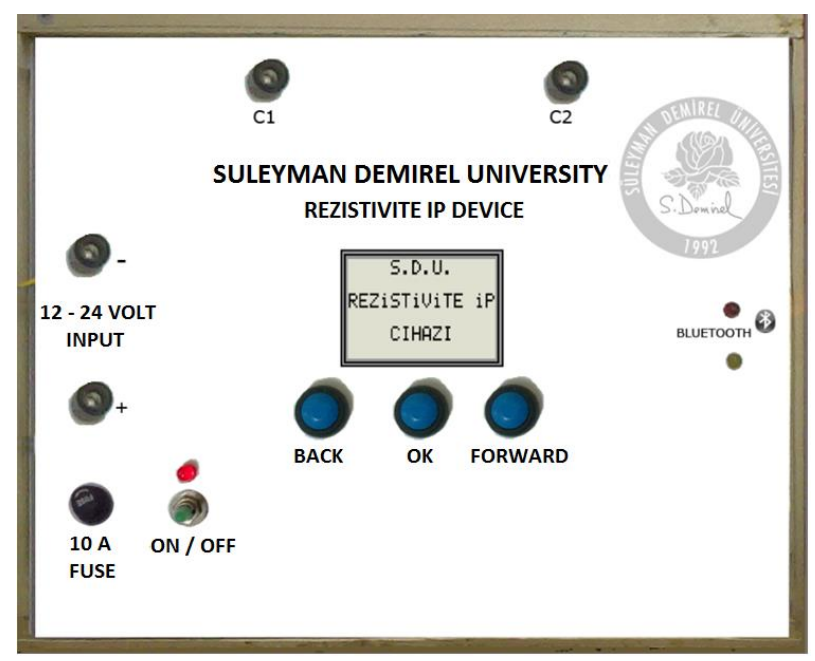

Figure 12

Topview of the transmitter unit

\subsection{Receiver Unit}

The receiver unit monitors the voltage value on the underground substance, which is produced by the current sent underground.

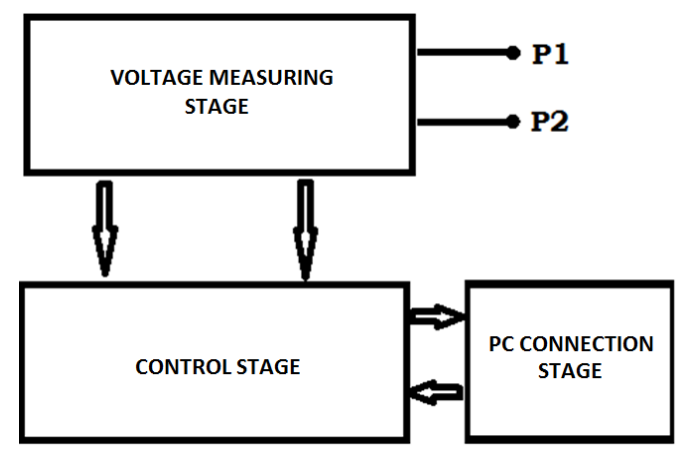

Figure 13

Block diagram of the receiver unit

In order to measure the voltage on the substance underground, a circuit that is sensitive to different frequencies was designed. The Figure consists of three main parts as shown in Figure 13. These consist of the voltage measuring stage, control stage, and PC connection stage. The PC connection stage has the same function and circuit with the PC connection stage of the transmitter unit. 


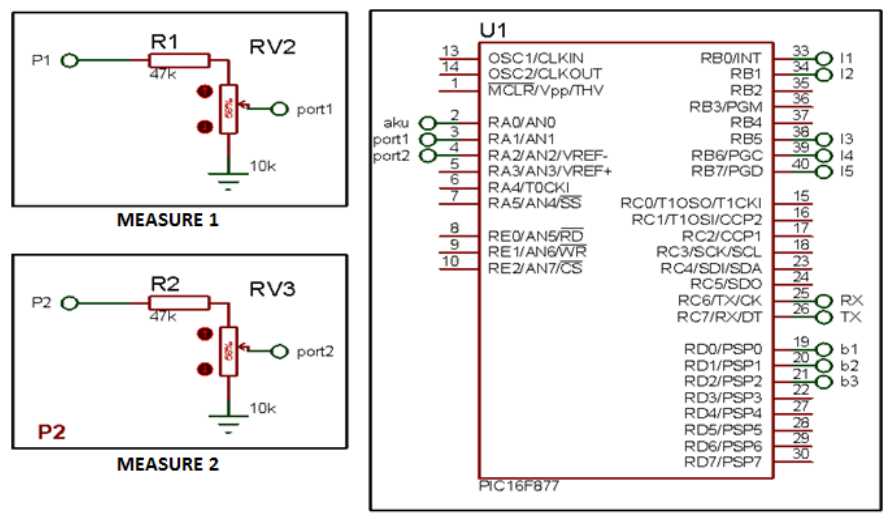

Figure 14

Circuit diagram of the voltage measuring stage of the receiver unit

The A1 and A2 ADC input of the PIC16F877 microcontroller used in the receiver unit circuit, which is pictured in Figure 14, is designed in a way that it receives voltage data in an analogue format from underground. The voltage value received from underground is sent to a PC via the PC connection stage, which is connected to the PIC.

A topview of the receiver unit is seen in Figure 15.

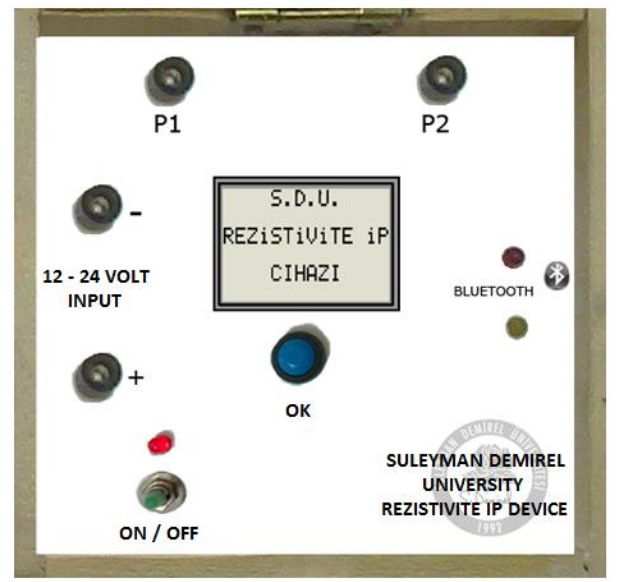

Figure 15

Topview of the receiver unit

\subsection{Computer Software}

Visual Studio editor software was used to evaluate the data received from the transmitter and receiver units. 


\subsubsection{Operating the Software and Interpreting the Data}

The main format of the program is seen in Figure 16.

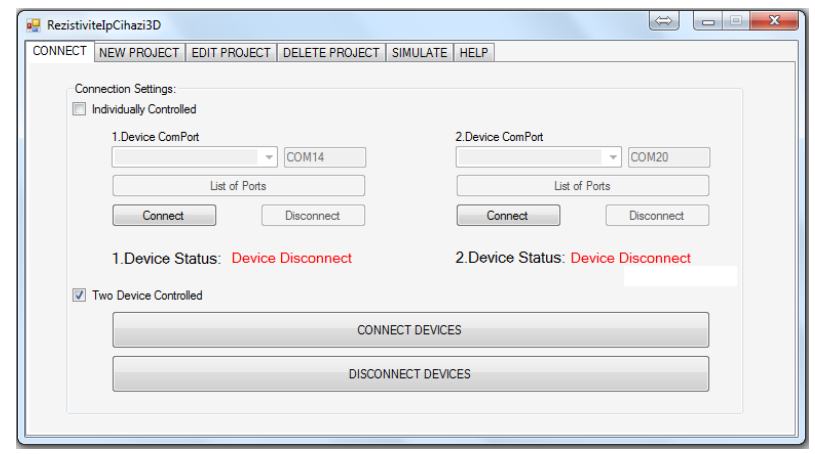

Figure 16

Connection window with transmitter and receiver units

The program used in this study realizes the connection between the transmitter and receiver units, and the connection of these two units with the computer via bluetooth. The program provides the opportunity to control these two units from the computer simultaneously, as well as separately.

It has another significant advantage in that the program evaluates the data received from the transmitter and receiver units; it also possesses a database. Recording the data received from the units in the database provides the opportunity to revise the previous studies.

In the process of receiving data from the transmitter and receiver units, the form in Figure 17 was used.

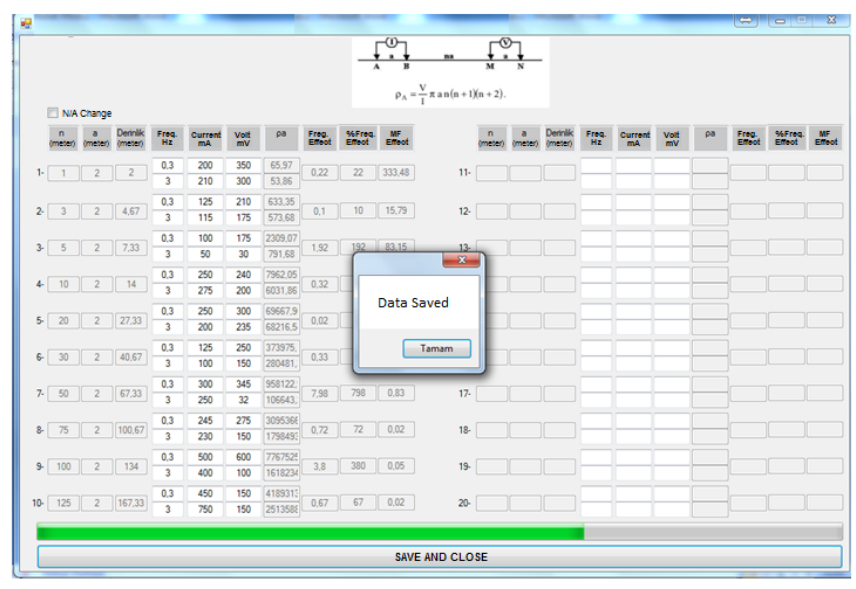

Figure 17

The screen shows the chart in which the data from the transmitter and receiver units are to be saved 
The form in Figure 17 is the screen that shows the current and voltage data measured vertically from a single point underground. Frequency, and current and voltage data received from the transmitter and receiver units arrive in a string, and the related parts in the form screen are completed, then saved. This process is repeated for every point to be measured vertically from ground to underground.

\section{Results and Discussion}

The comparison of the data recorded in the Beşirli Region of the Trabzon Province in Turkey using the proposed study system/device and the RVA-1 brand system/device is provided in Table 2 .

Table 2

Measured Rhoa values

\begin{tabular}{|c|c|c|c|}
\hline $\mathrm{AB} / 2$ & $\mathrm{MN} / 2$ & $\begin{array}{c}\text { Other device } \\
\text { (Rhoa) }\end{array}$ & $\begin{array}{c}\text { Proposed study device } \\
\text { (Rhoa) }\end{array}$ \\
\hline 2 & 0.5 & 7.7 & 7.83 \\
\hline 3 & 0.5 & 7.12 & 6.98 \\
\hline 4 & 0.5 & 6.64 & 6.47 \\
\hline 5 & 0.5 & 7.16 & 7.08 \\
\hline 6 & 0.5 & 6.58 & 6.4 \\
\hline 5 & 1 & 6.3 & 6.3 \\
\hline 6 & 1 & 5.82 & 5.9 \\
\hline 8 & 1 & 7 & 7.1 \\
\hline 10 & 1 & 8.8 & 8.5 \\
\hline 15 & 1 & 9.2 & 9.34 \\
\hline 20 & 1 & 9.34 & 9.34 \\
\hline 25 & 1 & 9.9 & 10.08 \\
\hline 30 & 1 & 10.6 & 10.3 \\
\hline 25 & 5 & 11 & 10.9 \\
\hline 30 & 5 & 11.7 & 11.5 \\
\hline 35 & 5 & 12.7 & 12 \\
\hline 40 & 5 & 13.5 & 13.5 \\
\hline 50 & 5 & 13.8 & 13.7 \\
\hline
\end{tabular}

The data obtained with these two systems were roughly similar. Using the data in Table 2, graphs were drawn for the vertical electrical sounding (VES) curves of the measured points. These VES curves are shown in Figure 18a and 18b.

It can be seen that the VES curves of the graphs in Figure $18 \mathrm{a}$ and $18 \mathrm{~b}$ are of the same character. 


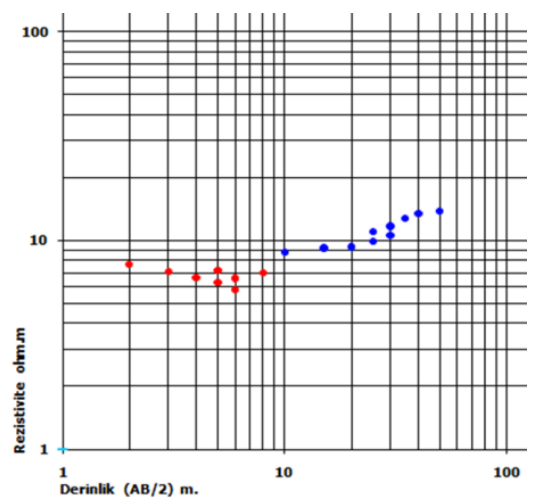

(a)

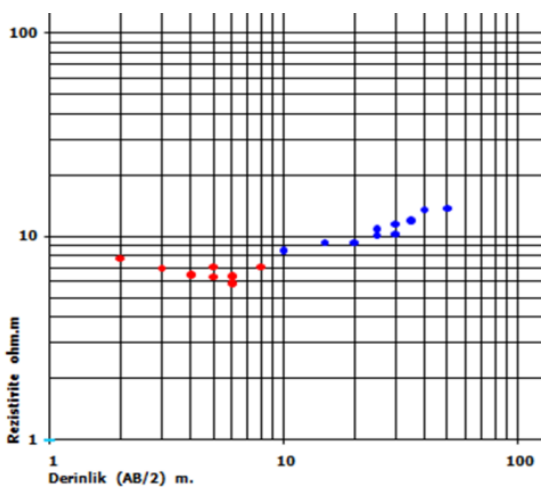

(b)

Figure 18

a: VES curve of the RVA-1 system, b: VES curve of the proposed study system

The graphs in Figure 19 (Rhoa1, Rhoa2, the frequency effect, and the frequency effect percentage) are 3-dimensional representations that use shades of black to illustrate the shapes formed by the underground layers.

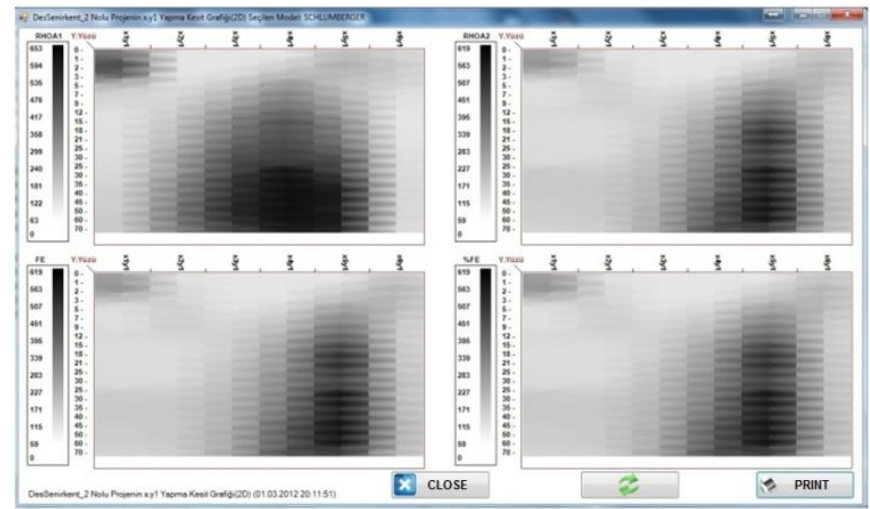

Figure 19

2D Simulative profile graphic

\section{Conclusions}

In this study, in order to identify the physical and chemical features underground, a resistance device that sends direct or alternating current underground, as well as transfers the current sent underground, and the resulting voltage that is released to the PC through a wireless process, was designed and implemented. In an attempt to identify the nature of the substances underground, the current sent from the power stage of the system should be strong; it affects the accuracy of the results to a large extent. 
The most significant advantage of this system is that the transmitter and the receiver units are not integrated and these two units can connect to computer wirelessly. A wireless connection provides significant savings from the cable cost and relieves the users from cable confusion.

A system was generated in C\# programming language, which enables a bluetooth connection between the receiver unit, transmitter unit, and PC for the graphic interpretation of the data received through the system. It also saves and interprets the data on the database. The software saves the data from the DES model and simulative profile model, as well as draws the graphics.

The fact that the number of studies regarding the development of geophysics devices is very limited, as well as the fact that there is very little information available on the operating rationale of such systems, have led to considerable difficulties during the development of the study device/system. Taking into consideration the development processes for technologies in general, the authors hope that this study will serve as a basis for the use of more advanced microprocessors and computers within the study system, which will ensure creation of systems that provide more accurate data.

\section{References}

[1] S. Akpancar: "Rezistivite-IP Alıcı / Verici Tasarımı ve PC'de Verilerin Analizi”, Suleyman Demirel University Graduate School of Natural and Applied Sciences Department of Electronic and Computer Education M.Sc. Thesis, Isparta, Turkey, 2012

[2] F. Ergüder, L. Karaoğlu: "Yeraltı Yapılarının Özdirenç Yöntemiyle Saptanması ve Uygulamaları", Turkey 5 coal Congres, 10p, 1983

[3] A. Uluğ: "Jeofizikte Veri İşlem", Dokuz Eylul University Faculty of Engineering and Architecture Lecture Notes, 1988

[4] M. A. Berge: "Iki Boyutlu Özdirenç Ters Çözüm Modellemesi", Dokuz Eylul University Faculty of Engineering Department of Geophysical Engineering M.Sc. Thesis, 2005

[5] M. E. Candansayar: "Doğru Akım Özdirenç Yönteminde Modelleme Ve İki Boyutlu Siğ Yapıların Aranmasında Elektrot Dizilimlerinin Ayrımlılıklarının Karşılaştırılması”, Ankara University Institute of Science M.Sc. Thesis, 1997

[6] A. Çakır: "Genliği Ve Frekansı Ayarlanabilen Konvertör Tasarımı Ve Yapımı", Gazi University Institute of Science M.Sc. Thesis, 1997

[7] Ş. Yıldız, E. Ölmez, F. Ataselim: “Odayeri Katı Atık Düzenli Depolama Sahası Depo Gövdesindeki Su Muhtevasının Doğal Potansiyel Ve Elektrik Özdirenç Yöntemleri Kullanılarak Tespiti”, Symposium on Solid Waste Management in Turkey, 5p, 2009 
[8] A. Kara: "Genel Jeofiziğe Giriş", Suleyman Demirel University Faculty of Engineering and Architecture Lecture Notes, 36p, 2010

[9] N. Coşkun: "Yer Elektrik Yöntemleri III: İndüksiyon Polarizasyonu (IP) Yöntemi”, Karadeniz Technical University Faculty of Engineering Lecture Notes, 2009

[10] A. T. Başokur: Maden Aramalarında Elektrik ve Elektromanyetik Yöntemler, Ankara University Faculty of Engineering Department of Geophysical Engineering, 43p, 2003

[11] J. Dudrik, J. Oetter, High-Frequency Soft-Switching DC-DC Converters for Voltage and Current DC Power Sources, Acta Polytechnica Hungarica, Vol. 4, No. 2, 2007, pp. 29-46

[12] Datasheetcatalog: [Online]. Available: http://www.datasheetcatalog.org/ datasheets/166/373875_DS.pdf, 2012 